\begin{tabular}{|c|c|c|}
\hline \multirow{3}{*}{$\begin{array}{r}\text { Case Reports in } \\
\text { Gastroenterology }\end{array}$} & \multirow{2}{*}{\multicolumn{2}{|c|}{ Case Rep Gastroenterol 2014;8:319-323 }} \\
\hline & & \\
\hline & $\begin{array}{l}\text { DOI: 10.1159/000368551 } \\
\text { Publisned online: Uctober 8, } 2014\end{array}$ & $\begin{array}{l}\text { (c) } 2014 \text { S. Karger AG, Basel } \\
\text { 1662-0631/14/0083-0319 } \$ 39.50 / 0 \\
\text { www.karger.com/crg }\end{array}$ \\
\hline & \multicolumn{2}{|c|}{$\begin{array}{l}\text { This is an Open Access article licensed under the terms of the Creative Commons } \\
\text { Attribution-NonCommercial } 3.0 \text { Unported license (CC BY-NC) (www.karger.com/OA- } \\
\text { license), applicable to the online version of the article only. Distribution permitted for non- } \\
\text { commercial purposes only. }\end{array}$} \\
\hline
\end{tabular}

\title{
Autoimmune Hepatitis with Multiple Sclerosis and Graves Disease: Coincidence or Association?
}

\author{
Omar N. Nadhem Mohammed Al Janabi Abdel Rahman Omer \\ Bang Wan \\ Internal Medicine Department, Texas Tech University Health Sciences Center, \\ Amarillo, Tex., USA
}

\section{Key Words}

Autoimmune hepatitis · Multiple sclerosis · Anti-smooth muscle antibodies · Interferon

\begin{abstract}
Autoimmune hepatitis (AIH) is a generally progressive, chronic hepatitis of unknown cause that occurs in children and adults of all ages. It is associated with a variety of autoimmune conditions like thyroid disorders (Hashimoto and Graves disease), celiac disease and multiple sclerosis (MS). We report the case of a 61-year-old woman with MS (untreated) and a history of Graves disease who presented with fatigue and right upper quadrant abdominal pain. She was admitted to our hospital for evaluation. Clinical and laboratory workup revealed AIH. She was successfully treated with prednisone and azathioprine, with complete clinical and laboratory improvement. However, to our knowledge there have been only a few reports of a possible association between AIH and untreated MS.

(c) 2014 S. Karger AG, Basel
\end{abstract}

\section{Introduction}

Autoimmune hepatitis (AIH) is a generally progressive, chronic hepatitis of unknown cause that occurs in children and adults of all ages. Occasionally it has a fluctuating course, with periods of increased or decreased activity [1]. It is a multifactorial polygenic disorder that is probably caused by the interaction of a trigger and environmental factors in a genetically susceptible individual [2]. It affects mainly females and has a varied clinical presentation from minor symptomatology to acute liver failure [3]. It is characterized serologically by high levels of alanine aminotransferase (ALT), aspartate aminotransferase (AST) and immunoglobulin G (IgG) and by the presence of autoantibodies, and histologically 
Nadhem et al.: Autoimmune Hepatitis with Multiple Sclerosis and Graves Disease: Coincidence or Association?

by interface hepatitis in the absence of a known cause of liver disease [4, 5]. Adequately dosed steroids are the mainstay of remission induction treatment, while remission maintenance is best achieved by azathioprine [6]. AIH is associated with other autoimmune diseases such as thyroiditis, ulcerative colitis, celiac disease, type 1 diabetes mellitus and rheumatoid arthritis [3]. Many reports have documented the association between multiple sclerosis (MS) in patients who are being treated with interferon beta, steroids and/or glatiramer acetate and the development of hepatitis (either drug-induced or autoimmune). Very rare reports however describe the association between untreated MS and AIH. We report a case of untreated MS and a history of Graves disease who developed AIH.

\section{Case Report}

A 61-year-old white woman presented in February 2013 with fatigue, decreased appetite and right upper quadrant abdominal pain for 2 weeks. She denied nausea, vomiting, weight loss and jaundice. Two weeks prior to presentation, the patient was found to have elevated liver enzymes by routine blood workup (AST 151 IU/l, ALT 199 IU/l), for which atorvastatin and ezetimibe were both discontinued (although she had been taking both for a long time). She was known to have MS (as she had clumsiness and optic neuritis with white matter hyperintensities by brain MRI, at that time not on any treatment, but treated with interferon in 2000 with resulting drug-induced hepatitis which resolved after discontinuation of interferon), hypothyroidism on levothyroxine (secondary to radioactive iodine ablation for Graves disease), hyperlipidemia and asthma.

On physical examination, blood pressure was $113 / 77 \mathrm{~mm} \mathrm{Hg}$, heart rate 64 beats/min and temperature $36.3^{\circ} \mathrm{C}$. She was not jaundiced and her heart and respiratory sounds were normal. Her abdomen was soft, not tender, not distended, without hepatomegaly or splenomegaly and with normal bowel sounds. She was alert and oriented, the cranial nerves were grossly intact, muscle bulk, tone and power were normal, there was no sensory deficit, and coordination and gait were both unremarkable. Laboratory tests on admission revealed white blood cells $6.1 \times 10^{3} / \mu \mathrm{l}$, hemoglobin $14 \mathrm{~g} / \mathrm{dl}$, platelets $433 \times 10^{3} / \mu \mathrm{l}$, sodium 138 $\mathrm{mEq} / \mathrm{l}$, potassium $4.6 \mathrm{mEq} / \mathrm{l}$, chloride $103 \mathrm{mEq} / \mathrm{l}$, bicarbonate $29 \mathrm{mmol} / \mathrm{l}$, BUN $11 \mathrm{mg} / \mathrm{dl}$, creatinine $0.7 \mathrm{mg} / \mathrm{dl}$ and glucose $94 \mathrm{mg} / \mathrm{dl}$. Liver function test showed AST 1,740 IU/l, ALT 1,497 IU/l, alkaline phosphatase (ALP) $140 \mathrm{IU} / \mathrm{l}$, total bilirubin $2.4 \mathrm{mg} / \mathrm{dl}$ (direct bilirubin 1.3) - later on it went up to $5.1 \mathrm{mg} / \mathrm{dl}$, gamma-glutamyl transferase (GGTP) $501 \mathrm{IU} / \mathrm{l}$ (normal 7-64 IU/l), total protein $8.3 \mathrm{~g} / \mathrm{dl}$ and albumin $3.8 \mathrm{~g} / \mathrm{dl}$. Coagulation panel showed prothrombin time $13.6 \mathrm{~s}$, international normalized ratio 1.44 and partial thromboplastin time $30.9 \mathrm{~s}$. Urine drug screen was negative. The results of thyroid function testing were thyroidstimulating hormone $10.3 \mathrm{mIU} / \mathrm{ml}$ and free thyroxine $0.8 \mathrm{ng} / \mathrm{dl}$. She had normal alphafetoprotein and a negative ethanol level. Serum protein electrophoresis showed high gamma fraction of protein $2.1 \mathrm{~g} / \mathrm{dl}$. Viral hepatitis was ruled out by negative hepatitis panel including negative hepatitis C virus RNA PCR. Complete serological tests revealed positive anti-smooth muscle antibodies at 1:320 (normal titer $<1: 40$ ), negative anti-mitochondrial antibodies, negative anti-nuclear antibodies, negative anti-neutrophil cytoplasmic antibodies, negative anti-myeloperoxidase antibodies, negative proteinase- 3 antibodies and negative liver kidney microsomal antibodies. Ultrasound of the liver was performed and showed no significant abnormality in the liver, gallbladder or pancreas. There was no sign of gallstone or pericholecystic fluid formation. Abdominal computed tomography with contrast showed only mild fatty changes of the liver. 
Nadhem et al.: Autoimmune Hepatitis with Multiple Sclerosis and Graves Disease: Coincidence or Association?

While the patient was in the hospital, ultrasound-guided liver biopsy was done; she was started on oral prednisone $60 \mathrm{mg}$ daily and discharged home on that dose awaiting the liver biopsy result. Later on this confirmed our diagnosis of AIH as it showed lobular lymphoplasmacytic infiltrate (fig. 1), Councilman bodies and spotty necrosis. Bile duct damage and bridging periportal fibrosis were present (fig. 2). In March 2013, the patient had improved clinically. Her liver enzymes were checked while she was still taking 60 mg prednisone daily with the following values: AST 360 IU/l, ALT 602 IU/l, ALP 92 IU/l, GGTP $398 \mathrm{IU} / \mathrm{l}$ and total bilirubin $2.9 \mathrm{mg} / \mathrm{dl}$. After receiving the liver biopsy result, she was prescribed oral azathioprine $50 \mathrm{mg}$ daily while tapering the prednisone dose. Her liver function was periodically checked with continuous improvement. In April 2013, she was taking both $20 \mathrm{mg}$ prednisone and $50 \mathrm{mg}$ azathioprine daily. In June 2013, the azathioprine was stopped and she was kept on oral prednisone $10 \mathrm{mg}$ daily, which later on (in September 2013) was decreased to $5 \mathrm{mg}$ daily. Her liver function has been always within the normal range since July 2013 with AST $40 \mathrm{IU} / \mathrm{l}$, ALT $35 \mathrm{IU} / \mathrm{l}$, ALP 37 IU/l, total bilirubin $0.9 \mathrm{mg} / \mathrm{dl}$, GGTP $60 \mathrm{IU} / \mathrm{l}$, total protein $6.8 \mathrm{~g} / \mathrm{dl}$ and albumin $3.9 \mathrm{~g} / \mathrm{dl}$.

\section{Discussion}

MS is an inflammatory demyelinating disease of the central nervous system. Liver dysfunction in MS can result from many factors, such as drug toxicity, fatty infiltration, viral infection, and sometimes as part of the autoimmune process. AIH is a rare disease with an estimated prevalence of approximately $10-50 / 100,000$ in the Western population, with a strong predominance in middle-aged women [7]. The female:male ratio in type $1 \mathrm{AIH}$ is about 4:1, but the ratio is 10:1 in type 2 disease [2]. Patients may present with nonspecific symptoms of varying severity, such as fatigue, lethargy, nausea, abdominal pain and itching. Arthralgia involving the small joints is common. Physical examination may reveal no abnormalities, but it may also reveal hepatomegaly, splenomegaly, jaundice as well as signs and symptoms of chronic liver disease [1]. The diagnostic features include biochemical evidence of transaminitis (elevated AST and ALT), elevated IgG, positive autoantibodies and histological features of hepatitis in the absence of viral disease $[3,6]$. The disease is classified into at least two types based on the autoantibody profile. Thus, AIH-1 is characterized by the presence of anti-smooth muscle antibodies and/or anti-nuclear antibodies, whereas reactivity to anti-liver kidney microsome antibodies type 1 and/or anti-liver cytosol antibodies type 1 defines AIH-2 [1]. All patients with suspected AIH should undergo liver biopsy. Not only does liver biopsy provide histological confirmation of AIH, but it may also help identify the presence of other liver diseases that can mimic the biochemical and serological features of AIH [8]. Interface hepatitis is typical of, though not exclusive to, AIH. Interface hepatitis is characterized by a lymphoplasmacytic infiltrate that crosses the limiting plate and invades the liver parenchyma [5]. Typically, the majority of patients respond within weeks to immunosuppressive therapy. Relief of clinical symptoms is followed by biochemical and histological remission [3]. Initial treatment with prednisone (or prednisolone) alone or in combination with azathioprine should be instituted in nearly all patients in whom the histological findings include interface hepatitis, with or without fibrosis or cirrhosis [1]. The target for remission therapy should be normalization of serum AST/ALT, gamma globulin, IgG and, ideally, histological evidence of cessation of active liver inflammation [3, 7]. Despite the availability of effective treatment, AIH is not a benign condition, with recent long-term studies reporting a two-fold higher mortality than that of the general population [9]. Incomplete normalization of ALT at 6 months, low serum albumin concentration at diagnosis 
Nadhem et al.: Autoimmune Hepatitis with Multiple Sclerosis and Graves Disease: Coincidence or Association?

and age of $<20$ years or $>60$ years were significant independent predictors of liver-related death or requirement for liver transplantation [9].

The association of AIH with primary biliary cirrhosis or primary sclerosing cholangitis has repeatedly been well documented. However, the association of AIH with autoimmune diseases other than primary biliary cirrhosis or primary sclerosing cholangitis has only rarely been described [10]. AIH is associated with a variety of autoimmune conditions like thyroid disorders (Hashimoto and Graves disease), celiac disease, MS [11] and other autoimmune diseases [6]. In addition, AIH had been reported in patients after exposure to certain drugs, including interferon [12] and methylprednisolone [13] for MS. It has been reported that in patients treated with interferon for hepatitis $\mathrm{C}$, AIH developed after a mean treatment duration of 4.8 years [14]. Our patient received interferon treatment 13 years ago for MS, which resulted in elevated liver function test, for which reason the treatment was stopped. Her liver enzymes normalized after the interferon was discontinued, but 13 years later she developed AIH. The elevation of her liver function test 13 years ago when she was exposed to interferon could have been drug-induced hepatic injury or an unmasking of dormant AIH. Given the long period of normal liver function after discontinuation of interferon, the former is favored.

In conclusion, the prevalence of AIH seems to be higher in patients with MS than in the general population. Attention should be paid to the development of AIH, whether after pulsed methylprednisolone or interferon beta treatment, in patients with MS or even in untreated MS patients.

\section{Disclosure Statement}

The authors declare no conflict of interest. There were no funding sources.

\section{References}

1 Krawitt EL: Autoimmune hepatitis. N Engl J Med 2006;354:54-66.

-2 Heneghan MA, Yeoman AD, Verma S, Smith AD, Longhi MS: Autoimmune hepatitis. Lancet 2013;382: 1433-1444.

3 Kriese S, Heneghan MA: Autoimmune hepatitis. Medicine 2011;39:580-584.

-4 Eugène C: Comment on the British Society of Gastroenterology guidelines for management of autoimmune hepatitis (part 1). Clin Res Hepatol Gastroenterol 2012;36:408-411.

5 Mieli-Vergani G, Vergani D: Autoimmune hepatitis. Nat Rev Gastroenterol Hepatol 2011;8:320-329.

6 Lohse AW, Mieli-Vergani G: Autoimmune hepatitis. J Hepatol 2011;55:171-182.

7 Manns MP: Autoimmune hepatitis: the dilemma of rare diseases. Gastroenterology 2011;140:1874-1876.

8 Efe C, Ozaslan E, Purnak T, Ozseker B, Kav T, Bayraktar Y: Liver biopsy is a superior diagnostic method in some patients showing the typical laboratory features of autoimmune hepatitis. Clin Res Hepatol Gastroenterol 2012;36:185-188.

-9 Ngu JH, Gearry RB, Frampton CM, Stedman CA: Predictors of poor outcome in patients with autoimmune hepatitis: a population-based study. Hepatology 2013;57:2399-2406.

$\checkmark 10$ Couto CA, Bittencourt PL, Porta G, Abrantes-Lemos CP, Carrilho FJ, Guardia BD, Cançado EL: Antismooth muscle and antiactin antibodies are indirect markers of histological and biochemical activity of autoimmune hepatitis. Hepatology 2014;59:592-600.

11 de Seze J, Canva-Delcambre V, Fajardy I, Delalande S, Stojkovic T, Godet E, Vermersch P: Autoimmune hepatitis and multiple sclerosis: a coincidental association? Mult Scler 2005;11:691-693.

$\checkmark 12$ Duchini A: Autoimmune hepatitis and interferon beta-1a for multiple sclerosis. Am J Gastroenterol 2002;97: 767-768. 
Nadhem et al.: Autoimmune Hepatitis with Multiple Sclerosis and Graves Disease: Coincidence or Association?

13 Takahashi A, Kanno Y, Takahashi Y, Sakamoto N, Monoe K, Saito H, Abe K, Yokokawa J, Irisawa A, Ohira H: Development of autoimmune hepatitis type 1 after pulsed methylprednisolone therapy for multiple sclerosis: a case report. World J Gastroenterol 2008;14:5474-5477.

14 Efe C, Heurgué-Berlot A, Ozaslan E, Purnak T, Thiéfin G, Simsek H, Wahlin S: Late autoimmune hepatitis after hepatitis C therapy. Eur J Gastroenterol Hepatol 2013;25:1308-1311.

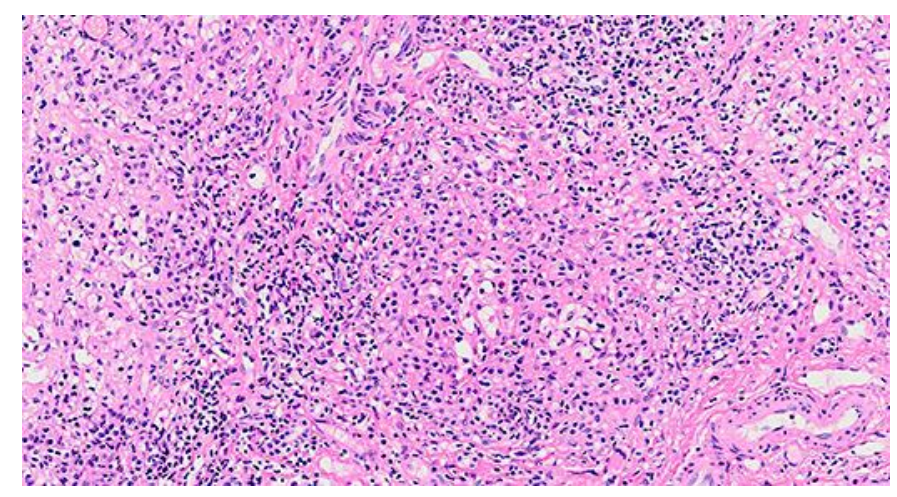

Fig. 1. Liver biopsy showed portal and lobular lymphoplasmacytic infiltrate by hematoxylin-eosin staining (original magnification $\times 200$ ).

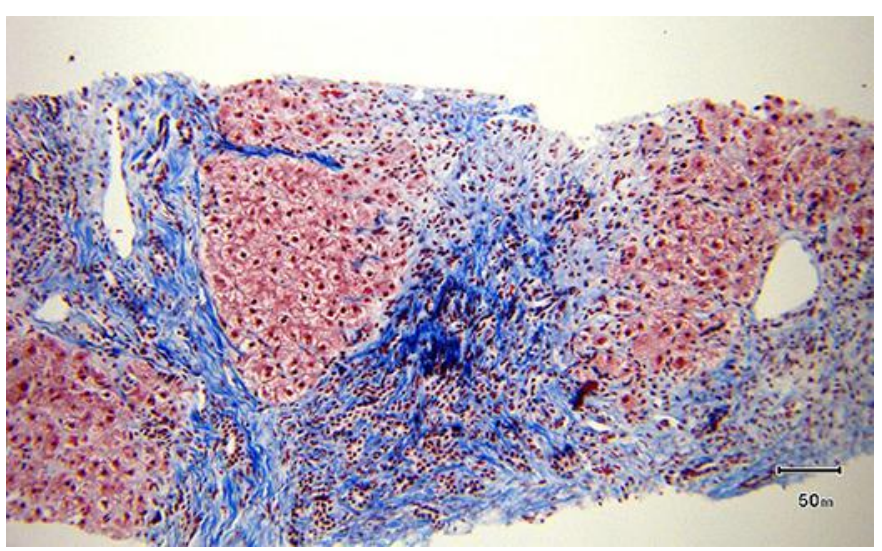

Fig. 2. Liver biopsy showed bridging fibrosis and cirrhotic nodules by trichrome staining (original magnification $\times 100$ ). 